\title{
ESTROGENIC ACTIVITY LEVEL OF NAKDONG RIVER BASIN AND ITS CONTROL BY WATER TREATMENT PROCESSES
}

\author{
Byoung-Cheun Lee*, Koichi Ohno*, Tasuku Kamei*, Yasumoto Magara*, \\ Shun-Hwa Lee**, Chul-Hee Lee** \\ *Graduate School of Engineering, Hokkaido University, N13, W8, Kita-ku, Sapporo, 060-8628, \\ Japan \\ **Department of Environmental Engineering, Yeungnam University, 214-1 Daedong, Kyungsan \\ City, 712-749, Korea
}

\begin{abstract}
During the past several years, concern has risen over potential pollution of waterways with estrogenic compounds, including steroidal hormones from human and animal sources. However, it is unclear whether the concentrations of estrogenic substances present in the environment are sufficient to cause adverse physiological effects. In spite of the fact that it is the receiving body for the sewage coming from a big city and an industrial area, Nakdong River water is used as a source for waterworks from the upstream to the downstream of the river. As such, it poses a threat as having potential to cause adverse health effects in humans and wildlife. The aim of this research is to evaluate estrogenic activity and concentrations of endocrine disruptors in this water environment. Examination of Nakdong River basin revealed that estrogenic substances and activity are distributed over the entire middle and downstream area but excluding the upstream. Estrogenic activity cannot be sufficiently removed by conventional activated sludge treatment, but can be reduced entirely by oxidation processes such as prechlorination and the combination of sand filtration and ozonation in sewage treatment plants (STPs) or water treatment plants (WTPs). During water-purifying processing, estrogenic activity decreased significantly with prechlorination followed by coagulation and sedimentation treatment.
\end{abstract}

\section{KEYWORDS}

Nakdong River; Estrogenic activity; 17ß-estradiol; Estrone; APE; Ethinylestradiol

\section{INTRODUCTION}

The potential threat of endocrine disrupting chemicals (EDCs) to wildlife and humans has been widely debated (EPA Report, 1997). The effects of endocrine-disrupting chemicals (EDCs) on man and other animals are of particular environmental concern. The scientific definition of an EDCs is "an exogenous substance that causes adverse health effects in an intact organism, or its progeny, consequent to endocrine function" (European Commission, 1996). Although most EDCs are man-made organic chemicals being introduced to the environment by anthropogenic inputs, they can also be naturally occurring in the environment. For example, the natural female hormones estrone and $17 \beta$-estradiol are both excreted by women and are, therefore, ubiquitous in aquatic environments receiving sewage inputs (J.C. Bowman, et. al., 2002). EDCs are either natural or synthetic and act as mimics or antagonists of endogenous hormones. It is well known that since the Nakdong River is contaminated by wastewaters coming from various industrial and domestic sources, it has the potential to cause adverse health effects in humans and wildlife. Yet, Nakdong River water, which may contain endocrine disrupters, is used as a source for waterworks from the upstream to the downstream of the river and also accepts the discharge from a big city and an industrial area. The aim of this research is to evaluate estrogenic activity and concentrations of endocrine disruptors in this water environment. 


\section{MATERIALS AND METHODS}

[Solid Phase Extraction (SPE) of samples] A sample was loaded into the Sep Pak C18 cartridge (Waters) that was conditioned with $20 \mathrm{ml}$ of dichloromethane and distilled water after filtration by a glass fiber filter (Whatman $\mathrm{GF} / \mathrm{B}$, previously rinsed with $\mathrm{MeOH}$ and dried). The SPE column was eluted by dichloromethane, and then the samples were blown down to dryness under a nitrogen gas stream and made up with dimethylsulfoxide (DMSO) for estrogenic activity measurement (concentration fold: 50,000).

[Assay for Estrogenic Activity and Concentration] Yeast Two-Hybrid Assay was used to evaluate the estrogenic activity. This bioassay detects real estrogens (such as $17 \beta$-estradiol, estrone, and estriol) as well as all known xenoestrogens (such as alkylphenol-ethoxylates and ethinylestradiol). Upon binding an active ligand, the occupied receptor then binds to the estrogen-response sequences (EREs) and interacts with transcription factors and other transcriptional components to modulate gene transcription. This causes expression of the reporter gene $L a c-Z$, and the enzyme produced ( $\beta$-galactosidase) is secreted into the medium where it metabolizes the chromogenic substrate, which is normally yellow, that can be measured by absorbance. The yeast cells were pre-incubated overnight at $30^{\circ} \mathrm{C}$ in SD medium. The culture was then mixed with a DMSO solution of test chemical and incubated for $4 \mathrm{hr}$ at $30^{\circ} \mathrm{C}$. After washing by centrifugation, the cells were digested enzymatically by incubation with $1 \mathrm{mg} / \mathrm{ml}$ Zymolyase $20 \mathrm{~T}$ at $30^{\circ} \mathrm{C}$ for $15 \mathrm{~min}$ and then enzymatic reaction was started by addition of $40 \mu l$ of $4 \mathrm{mg} / \mathrm{ml} 2$-nitrophenyl- $\beta$-D-galactoside (ONPG). When the yellow color developed, $100 \mu l$ of $1 \mathrm{M} \mathrm{Na}_{2} \mathrm{CO}_{3}$ were added to stop the reaction. And absorbance is measured at $420 \mathrm{~nm}$ (absorbance by $o$-nitrophenol) and $570 \mathrm{~nm}$ (light scattering at the end of reaction). $\beta$-galactosidase activity is calculated from the following equation.

$$
\text { Estrogenic activity }=1000 *\left(\mathrm{OD}_{420}-1.75 * \mathrm{OD}_{570}\right) /\left(\mathrm{OD}_{595} * \mathrm{t} * \mathrm{v}\right)
$$

where, $\mathrm{t}$ : time of reaction ( $\mathrm{min}), \mathrm{v}$ : volume of culture used in assay $(\mathrm{ml}), \mathrm{OD}_{420}$ : absorbance at the end of reaction, $\mathrm{OD}_{570}$ : light scattering at the end of reaction, $\mathrm{OD}_{595}$ : cell density at the start of the assay

The results were given to relative estrogenic activity, when the maximum estrogenic activity is $100 \%$ for E2 of $10^{-3} \mathrm{M}$ as the positive control. The concentration of $17 \beta$-Estradiol (E2), Estrone (E1), Alkylphenol-ethoxylates (APE), Ethinylestradiol (EE2) using Enzyme-Linked Immunosorbent Assay (ELISA, TAKEDA, JAPAN) kit applied by the antigen-antibody reaction was analyzed.

\section{RESULTS AND DISCUSSION}

Fig. 1 shows the sampling points along of Nakdong River in May, and October 2002 and in March, and September 2003. Samples were collected from 7 points in

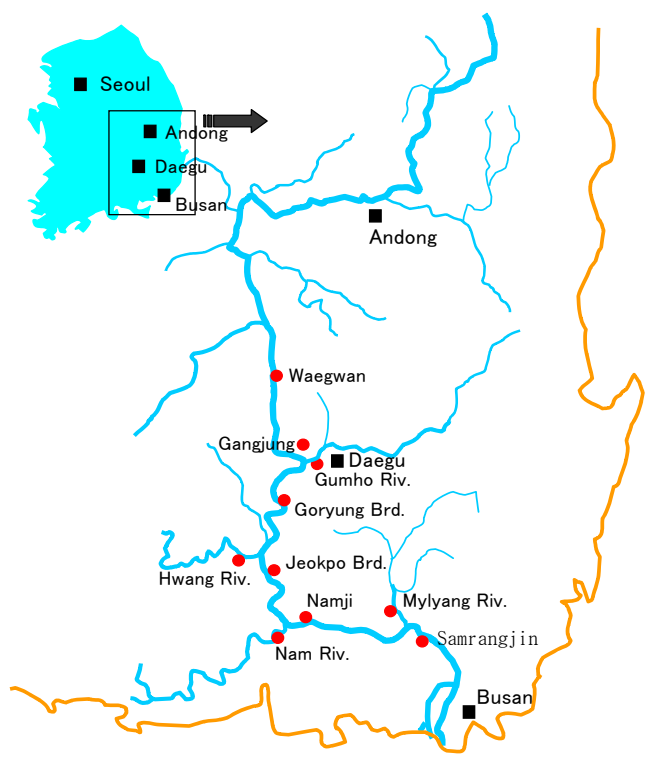

Fig. 1. Sampling points of Nakdong River basin 
the mainstream, 4 points in branch streams, water treatment plants, and sewage treatment plants one each from the upstream of Andong area to downstream of Busan area of Nakdong river basin.

\section{Estrogenic activity and concentration of estrogenic substances in the Nakdong River basin}

Relative estrogenic activity of the main and branch stream of Nakdong River basin is shown in Fig. 2 and seasonal fluctuation is obvious. Relatively lower estrogenic activity was observed for all sites excluding the Gumho River, where sewage coming from a big city and an industrial area was discharged regularly in September 2003, but due to dilution caused by a typhoon the effects were minimized. The Nakdong River water showed that estrogenic activity is distributed over the entired middle and downstream areas excluding the upstream Andong.

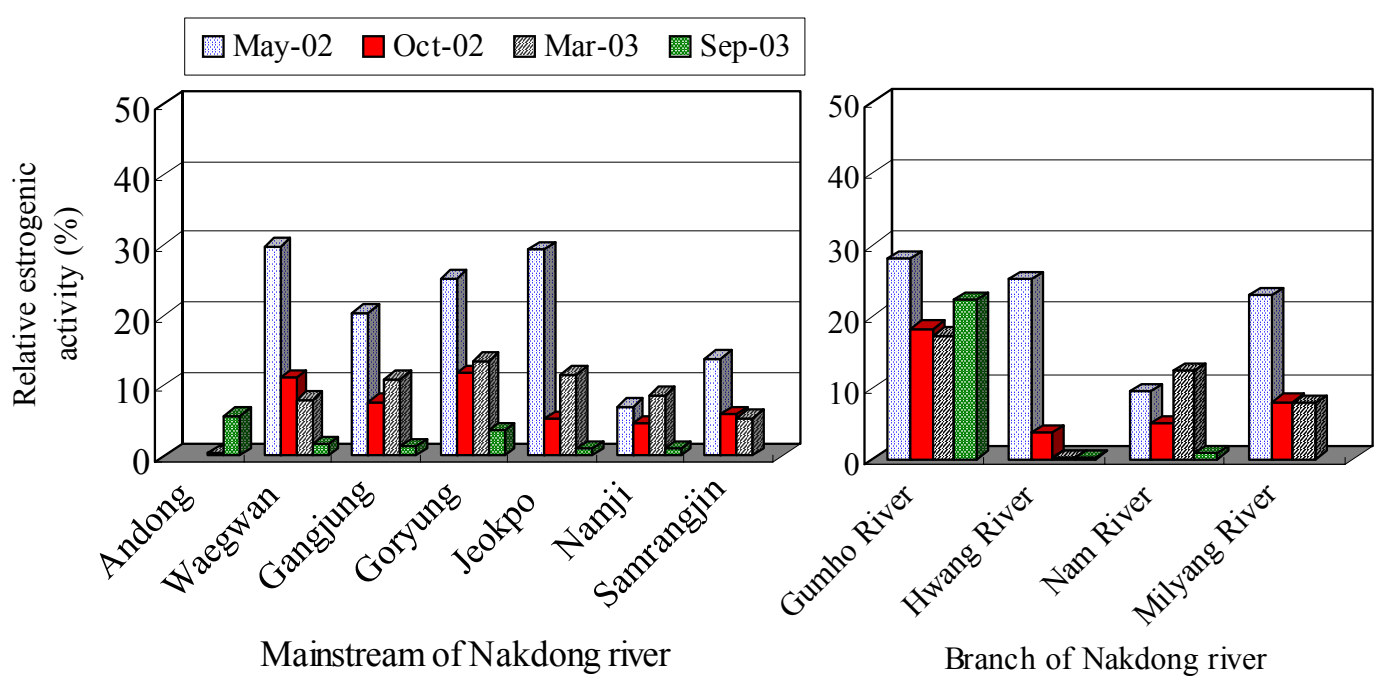

Fig. 2. Relative estrogenic activity according to the Yeast Two-hybrid assay in Nakdong River basin (concentration fold: 50,000).

Relative estrogenic activity is increased untill around 30\% at Waegwan and Jeokpo for the mainstream of Nakdong river basin in May, 2002. It is judged that estrogenic activity decreases by going to the lower stream of Nakdong river by dilution action or selfpurification. The estrogenic activity in downstream of Gumho River was observed regularly higher than other spots because it was the location where domesic and industrial wastewater from Daegu metropolitan city flows. It can be confirmed that the concentrations of the estrogenic substances such as EE2, E2, E1, and APE increases at Goryung and Gumho river (Table1). The estrogenic activity increased at every spot excluding Namji and Nam River in May 2002. Yeast Two-hybrid assay and ELISA method for Nakdong River water revealed that estrogenic substances and activity is distributed over the whole middle and downstream excluding the upstream of Andong.

\section{Relative estrogenic activity of estrogenic substances in the Sewage treatment plants and Water treatment plants}

The removal of estrogenic substances by conventional and advanced activated sludge treatment was estimated. Advanced purifying processes including ozonation and Granular Activated Carbon (GAC) process were also estimated. The activated sludge process makes it more 
possible to significantly lower EE2, E2, E1, and APE concentrations for the secondary treatment water and for ozone treatment water in the sewage treatment plants than for the inflow water (Figure 3 and Table 2). In domestic and industrial line, estrogenic activity significantly increased during the activated sludge process.

From the result of the step dilution about sample of 50000 fold, estrogenic activity of influent was observed higher than effluent as shown in Figure 3 (right hand side). Although estrogenic activity could not be sufficiently removed by conventional activated sludge treatment, it can be reduced to less than 5\% estrogenic activity level by the combination of sand filtration and ozonation processes.

Fig. 4 indicates the behavior of estrogenic activity for each purifying treatment process. For water-purifying processes, it appears that estrogenic activity decreased most significantly by coagulation and sedimentation.
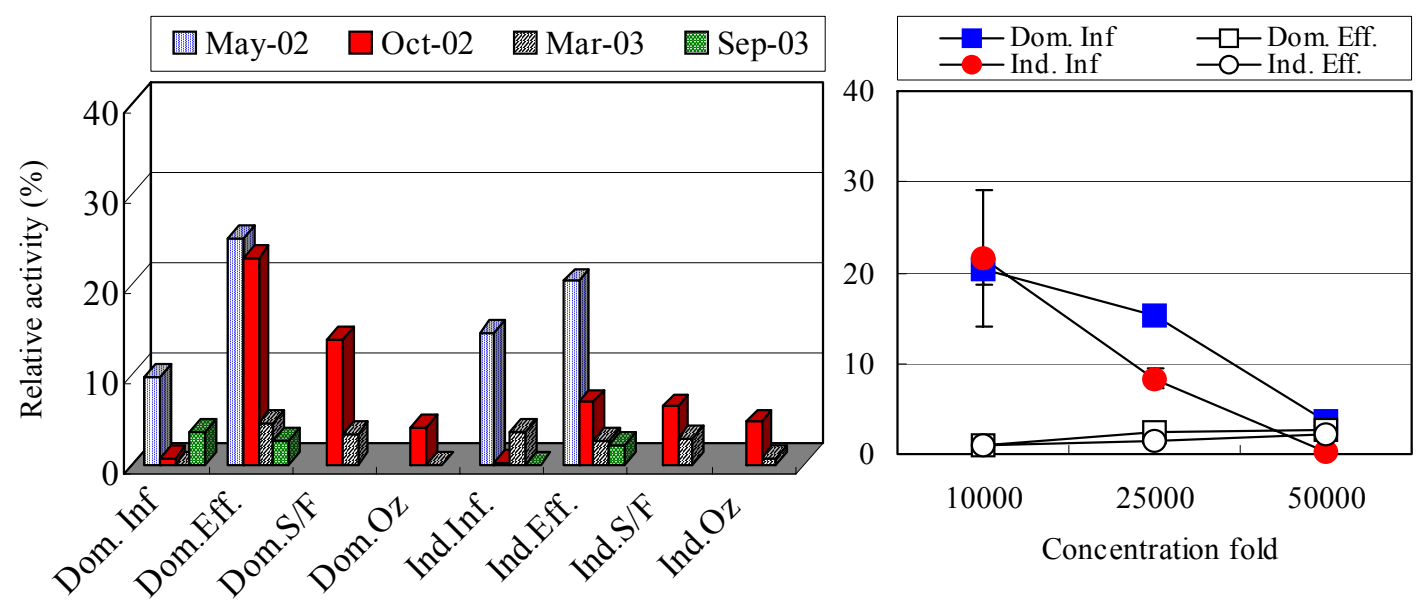

Fig. 3. Relative estrogenic activities in processes of domestic and industrial line (Concentration fold: 50,000 fold, left figure). Relative estrogenic activities were shown with step dilution up to 10000 times in each process. Error bars indicate the standard deviation (sample: September 2003) (right hand side).

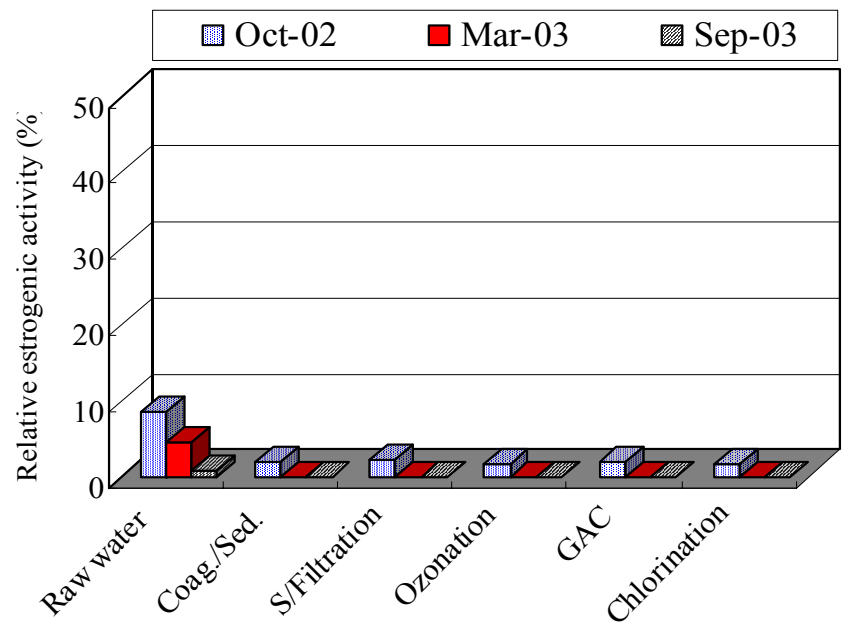

Fig. 4 Relative estrogenic activities in each process of water treatment plants. All samples were condensed up to 50,000 times. 
Table 1. Concentration of estrogenic substances in mainstream and branches of Nakdong River basin

\begin{tabular}{|c|c|c|c|c|c|}
\hline Sites & Date & EE2 ng/L \pm S.D. & E2 ng/L \pm S.D. & E1 ng/L \pm S.D. & APE ng/L \pm S.D. \\
\hline \multirow[t]{2}{*}{ Andong } & $3 / 03$ & $2.14 \pm 0.10$ & $1.43 \pm 0.09$ & $1.74 \pm 0.01$ & $0.62 \pm 0.01$ \\
\hline & $9 / 03$ & $0.72 \pm 0.03$ & $18.56 \pm 5.4$ & $1.25 \pm 0.05$ & $0.69 \pm 0.02$ \\
\hline \multirow[t]{4}{*}{ Waegwan } & $5 / 02$ & $0.11 \pm 0.01$ & $7.67 \pm 0.28$ & $1.03 \pm 0.02$ & $0.50 \pm 0.01$ \\
\hline & $10 / 02$ & $1.18 \pm 0.08$ & $0.50 \pm 0.03$ & $5.08 \pm 0.46$ & $0.51 \pm 0.09$ \\
\hline & $3 / 03$ & $1.93 \pm 0.06$ & $1.83 \pm 0.01$ & $3.14 \pm 0.02$ & $4.28 \pm 0.18$ \\
\hline & $9 / 03$ & $1.39 \pm 0.07$ & $2.53 \pm 0.72$ & $1.54 \pm 0.02$ & $1.88 \pm 0.06$ \\
\hline \multirow[t]{4}{*}{ Gangjung } & $5 / 02$ & $0.28 \pm 0.02$ & $8.22 \pm 0.62$ & $0.90 \pm 0.01$ & $0.51 \pm 0.01$ \\
\hline & $10 / 02$ & $0.71 \pm 0.05$ & $0.47 \pm 0.02$ & $1.89 \pm 0.20$ & $0.20 \pm 0.06$ \\
\hline & $3 / 03$ & $1.57 \pm 0.05$ & $1.86 \pm 0.04$ & $2.95 \pm 0.01$ & $3.17 \pm 0.10$ \\
\hline & 9/03 & $1.39 \pm 0.01$ & $1.63 \pm 0.04$ & $1.70 \pm 0.12$ & $1.00 \pm 0.01$ \\
\hline \multirow[t]{4}{*}{ Goryung } & $5 / 02$ & $1.66 \pm 0.12$ & $8.53 \pm 0.17$ & $3.17 \pm 0.06$ & $2.30 \pm 0.08$ \\
\hline & $10 / 02$ & $0.64 \pm 0.05$ & $1.40 \pm 0.07$ & $3.62 \pm 1.28$ & $0.65 \pm 0.01$ \\
\hline & $3 / 03$ & $3.82 \pm 0.05$ & $4.22 \pm 0.04$ & $4.84 \pm 0.03$ & $5.43 \pm 0.10$ \\
\hline & 9/03 & $1.31 \pm 0.07$ & $3.17 \pm 0.23$ & $1.80 \pm 0.13$ & $2.08 \pm 0.17$ \\
\hline \multirow[t]{4}{*}{ Jeokpo } & $5 / 02$ & $1.65 \pm 0.12$ & $8.20 \pm 0.23$ & $2.38 \pm 0.34$ & $1.44 \pm 0.06$ \\
\hline & $10 / 02$ & $1.03 \pm 0.07$ & $0.67 \pm 0.03$ & $2.71 \pm 1.01$ & $0.30 \pm 0.07$ \\
\hline & $3 / 03$ & $4.21 \pm 0.02$ & $3.69 \pm 0.01$ & $4.49 \pm 0.10$ & $6.56 \pm 0.16$ \\
\hline & $9 / 03$ & $1.53 \pm 0.19$ & $9.13 \pm 1.14$ & $1.62 \pm 0.01$ & $1.24 \pm 0.04$ \\
\hline \multirow[t]{4}{*}{ Namji } & $5 / 02$ & $1.69 \pm 0.11$ & $7.17 \pm 0.12$ & $3.96 \pm 0.18$ & $1.65 \pm 0.07$ \\
\hline & $10 / 02$ & $0.90 \pm 0.06$ & $0.45 \pm 0.02$ & $4.60 \pm 0.18$ & $0.11 \pm 0.04$ \\
\hline & $3 / 03$ & $4.54 \pm 0.10$ & $3.11 \pm 0.05$ & $4.16 \pm 0.12$ & $4.91 \pm 0.24$ \\
\hline & $9 / 03$ & $1.79 \pm 0.04$ & $2.18 \pm 0.48$ & $1.69 \pm 0.19$ & $0.97 \pm 0.04$ \\
\hline \multirow[t]{3}{*}{ Samrangjin } & $5 / 02$ & $1.17 \pm 0.08$ & $9.16 \pm 0.04$ & $2.95 \pm 0.12$ & $1.38 \pm 0.03$ \\
\hline & $10 / 02$ & $1.04 \pm 0.07$ & $0.32 \pm 0.02$ & $2.93 \pm 0.83$ & $0.27 \pm 0.06$ \\
\hline & $3 / 03$ & $2.74 \pm 0.04$ & $3.12 \pm 0.21$ & $4.18 \pm 0.18$ & $2.62 \pm 0.04$ \\
\hline \multirow[t]{4}{*}{ Gumho River } & $5 / 02$ & $1.24 \pm 0.09$ & $5.53 \pm 0.01$ & $5.47 \pm 0.58$ & $4.04 \pm 0.08$ \\
\hline & $10 / 02$ & $1.58 \pm 0.11$ & $0.35 \pm 0.02$ & $3.94 \pm 0.39$ & $0.16 \pm 0.07$ \\
\hline & $3 / 03$ & $3.27 \pm 0.02$ & $4.96 \pm 0.12$ & $7.93 \pm 0.08$ & $11.96 \pm 0.01$ \\
\hline & $9 / 03$ & $1.24 \pm 0.08$ & $36.87 \pm 7.29$ & $3.92 \pm 0.06$ & $13.27 \pm 0.93$ \\
\hline \multirow[t]{4}{*}{ Hwang River } & $5 / 02$ & $46.73 \pm 4.21$ & $15.05 \pm 0.37$ & $1.83 \pm 0.09$ & $0.96 \pm 0.01$ \\
\hline & $10 / 02$ & $1.82 \pm 0.13$ & $0.21 \pm 0.01$ & $4.97 \pm 1.20$ & $0.32 \pm 0.07$ \\
\hline & $3 / 03$ & $3.94 \pm 0.16$ & $3.31 \pm 0.03$ & $3.02 \pm 0.13$ & $1.23 \pm 0.03$ \\
\hline & $9 / 03$ & $1.38 \pm 0.04$ & $1.89 \pm 0.18$ & $1.46 \pm 0.09$ & $0.71 \pm 0.03$ \\
\hline \multirow[t]{4}{*}{ Nam River } & $5 / 02$ & $51.34 \pm 3.59$ & $16.2 \pm 0.11$ & $2.80 \pm 0.17$ & $1.06 \pm 0.02$ \\
\hline & $10 / 02$ & $1.75 \pm 0.12$ & $0.66 \pm 0.03$ & $4.14 \pm 0.41$ & $0.38 \pm 0.08$ \\
\hline & $3 / 03$ & $4.36 \pm 0.17$ & $3.23 \pm 0.02$ & $3.92 \pm 0.11$ & $2.20 \pm 0.09$ \\
\hline & $9 / 03$ & $1.68 \pm 0.01$ & $2.41 \pm 0.30$ & $1.83 \pm 0.08$ & $0.83 \pm 0.03$ \\
\hline \multirow[t]{3}{*}{ Mylyang River } & $5 / 02$ & $2.40 \pm 0.17$ & $7.62 \pm 0.17$ & $3.08 \pm 0.23$ & $1.31 \pm 0.02$ \\
\hline & $10 / 02$ & $1.19 \pm 0.08$ & $0.98 \pm 0.05$ & $3.87 \pm 0.32$ & $0.38 \pm 0.08$ \\
\hline & $3 / 03$ & $3.83 \pm 0.06$ & $3.01 \pm 0.23$ & $3.78 \pm 0.14$ & $2.20 \pm 0.09$ \\
\hline
\end{tabular}

Table 2. Concentration of estrogenic substances in sewage treatment plants (Number of sample $=4$ ) Point sewage treatment $\quad$ EE2 ng/L $\quad$ E2 ng/L $\quad$ E1 ng/L $\quad$ APE ng/L process

\begin{tabular}{lllll}
\hline Influent & $2.0-30.3$ & $0.1-10.7$ & $69.5-267.5$ & $39.0-163.2$ \\
Effluent & $1.4-4.3$ & $0.1-6.1$ & $5.9-17.9$ & $6.7-27.5$ \\
S/Filtration & $2.5-4.7$ & $2.4-8.2$ & $10.5-13.6$ & $12.4-12.6$ \\
Ozonation & $1.5-4.3$ & $0.7-3.1$ & $3.5-11.7$ & $1.4-5.7$ \\
\hline
\end{tabular}

LOD (limit of detection) EE2>0.64, E2>0.535 ng/L, E1>0.69, APE $>0.267 \mathrm{ng} / \mathrm{L}$ 
However, decrease in estrogenic activity is due to the prechlorination and the result shows that estrogenic activity is less than $5 \%$ at each process and these values indicated are much lower than valid levels. These values, however, can be reduced to below valid value by combination of sand filtration and ozonation. In case of measuring the estrogenic activity for the environmental water using Yeast Two-Hybrid method, the activity level is lower than expected due to hindrance actions of the coexistence substances.

\section{CONCLUSIONS}

In this research, investigation of the polluted situation in Nakdong River and estimation on the purification treatment method for removal of estrogenic substances were carried out.

Nakdong River basin revealed that estrogenic substances and activity is distributed over the whole middle and downstream excluding the upstream Andong spot. Although, estrogenic activity could not be sufficiently removed by conventional activated sludge treatment, it is reduced to less than 5\% estrogenic activity level by the combination of sand filtration and ozonation process in STPs. During water-purifying processing, estrogenic activity decreased due to prechlorination preceding coagulation and sedimentation processing (estrogenic activity: < $5 \%)$.

\section{REFERENCES}

Jun-ichi Nishikawa, Koichi Saito, Jun Goto, Fumi Dakeyama, Masatoshi Matsuo, and Tsutomu Nishihara (1999). New screening methods for chemicals with hormonal activities using interaction of nuclear hormone receptor with coactivator, Toxicology and Applied Pharmacology, 154, 76-83.

T.A. Ternes, P. Kreckel, J. Mueller, Behavior and occurrence of estrogens in municipal sewage treatment plants-2 (1999). Aerobic batch experiments with activated sludge, The Science of the total Environment, 225, 91-99.

Tasuku Kamei, Meea Kang, Hyunokoo Kim, Yuko Sato, Motoyuki Kamata, Yasumoto Magara (2002). Rapid and Comprehensive indicator for evaluating the performance of treatment processes, Proceeding of 2002 IWA World Water Congress, e20217a.

Kamata M., Evaluation of estrogenic activity of natural water by Yeast two-hybrid system, Doctoral dissertation, Hokkaido University, Japan, 2001 (in Japanese).

Byoung-Cheun Lee, Motoyuki Kamata, Yasushi Akatsuka, Makoto Takeda, Koichi Ohno, Tasuku Kamei, Yasumoto Magara (2004), Effect of chlorine on the decrease of estrogenic chemicals, Water Research, 38, 733-739.

Shosaku Kashiwada, Yuta Ohnishi, Hidenori Ishikawa, Nobukazu Miyamoto, and Yasumoto Magara (2001). Comprehensive Risk Assessment of Estradiol-17ß, Nonylphenol, and Bis-Phenol-A in River Water in Japan, Environmental Sciences, 8 (1), 89-102.

Diane M. Klotz, Barbara S. Beckman, Steven M. Hill, John A. McLachlan, Marian R. Walters, and Steven F. Arnold (1996). Identification of environmental chemicals with estrogenic activity using a combination of In vitro Assays. Environmental Health Perspectives, 104 (10), 1084-1089.

C. Desbrow, E.J. Routledge, G.C. Brighty, J.P. Sumpter, and M. Waldock (1998). Identification strogenic chemicals in STW effluent. 1. Chemical fractionation and In Vitro biological screening. Environmental Science and Technology, 32 (11), 1549-1558. 